\title{
Prognostic value of lung function and pulmonary haemodynamics in OSA patients treated with CPAP
}

\author{
A. Chaouat*, E. Weitzenblum*, J. Krieger**, E. Sforza**, H. Hammad*, M. Oswald*, R. Kessler*
}

Prognostic value of lung function and pulmonary haemodynamics in OSA patients treated with CPAP. A. Chaouat, E. Weitzenblum, J. Krieger, E. Sforza, H. Hammad, M. Oswald, R. Kessler. (C) ERS Journals Ltd 1999.

ABSTRACT: The aim of the present study was to determine survival rates of obstructive sleep apnoea patients treated with continuous positive airway pressure (CPAP) and to investigate the prognostic value of pretreatment lung function and pulmonary haemodynamics.

Two hundred and ninety-six patients, exhibiting $\geq 20$ apnoeas plus hypopnoeas per hour of sleep, were included. Patients were treated with nasal CPAP and regularly followed up.

The cumulative survival rates were 0.96 (95\% confidence interval (CI): $0.94-0.99)$ at 3 yrs and 0.93 (95\% CI: 0.91-0.97) at 5 yrs. Most patients died from cardiovascular disease. Apart from age, covariates associated with a lower survival were the presence of a heavy smoking history, a low vital capacity, a low forced expiratory volume in one second (FEV1) and a high mean pulmonary artery pressure. Only three covariates were included by forward stepwise selection in the multivariate analysis, smoking habit ( $>30$ pack-yrs), age and FEV1. The observed survival rates of the group as a whole were similar to those of the general population matched in terms of age, sex and smoking habit, except for patients between 50 and 60 yrs old who had reduced survival. This difference disappeared when patients of the present study with an associated chronic obstructive pulmonary disease were excluded from the comparison.

In conclusion, survival of obstructive sleep apnoea patients treated with nasal continuous positive airway pressure is near to that of the general population. The prognosis is worse in subgroups of patients with a history of heavy smoking and with an associated chronic obstructive pulmonary disease.

Eur Respir J 1999; 13: 1091-1096.
*Dept of Respiratory Medicine and **the Sleep Laboratory, University Hospital, Strasbourg, France.

Correspondence: A. Chaouat

Service de Pneumologie

Hôpital de Hautepierre

Avenue Molière

67098 Strasbourg Cedex

France

Fax: 33388127827

Keywords: Chronic obstructive pulmonary disease

continuous positive airway pressure

mortality

sleep apnoea syndrome

Received: July 281998

Accepted after revision January 131999
Obstructive sleep apnoea (OSA) syndrome is an important public health concern, since it is estimated to be present in $\sim 2 \%$ of females and $4 \%$ of males in a middle-aged population [1]. Major symptoms are excessive daytime sleepiness and snoring [2]. Life-threatening complications such as cor pulmonale [3], arrhythmias and cardiac insufficiency [4] occur in a minority of patients. However, retrospective studies have suggested that mortality could be significantly higher in these patients than in the general population $[4,5]$. This has led to the establishment of therapies for OSA, the most efficient one being nasal continuous positive airway pressure (CPAP), initially described by SulLivan et al. [6].

Nasal CPAP prevents upper airway obstruction and allows a nondisturbed sleep. It has been reported that the acceptance of this treatment is relatively high in large series of OSA patients and that side-effects, although frequent, are generally minor [7]. Long-term use of nasal CPAP is effective in improving daytime arterial blood gases in severely obese OSA patients [8]. Furthermore, He et al. [5] reported that OSA patients treated with nasal CPAP had a better survival compared to untreated patients.

Currently, most patients diagnosed with OSA are treated with nasal CPAP which raises ethical problems as to how to set up randomized trials comparing patients receiving nasal CPAP with untreated patients. Nevertheless, information about the long-term effect of nasal CPAP could be obtained from the outcome of OSA patients undergoing CPAP therapy. Long-term physiological effects of this treatment have been studied by several groups [8-11] whereas there have been very few studies $[5,12]$ examining survival in OSA patients treated with nasal CPAP. None of these studies has examined the prognostic value of pulmonary function variables at the start of the therapy.

Thus, the aim of the present study was to determine the mortality rate in a large series $(n=296)$ of unselected OSA patients treated with nasal CPAP and to evaluate the prognostic value of smoking habits, lung function data, arterial blood gases and pulmonary haemodynamics.

\section{Patients and methods}

The eligible population consisted of patients referred to the authors' Sleep Disorders Unit for a suspected diagnosis of OSA from December 1983 to October 1992. Inclusion criteria were the polysomnographic demonstration of $\geq 20$ apnoeas plus hypopnoeas per hour of sleep ( $>80 \%$ of 
them being of the obstructive type) and the acceptance of home treatment with nasal CPAP. Spirometry and arterial blood gas determination were performed in all patients before starting nasal CPAP. It was planned to perform right heart catheterization in every patient when there was no contra-indication. All the patients gave informed consent. Patients were not investigated during an acute exacerbation of the disease (pulmonary infection, acute bronchitis, episode of right heart failure or of acute respiratory failure). The time elapsed between any such episode and the day of investigation was at least 6 weeks. Patients who had at the baseline evaluation a very low life expectancy owing to malignancies or end-stage organ failure were excluded from the study. Pulmonary haemodynamic data [13] as well as long-term physiological effects of nasal CPAP [11] of a subgroup of patients included in this study have been published previously.

Polysomnography was performed on consecutive nights, without (diagnostic night) and with CPAP, as part of baseline evaluation. The method has been described previously [10]. Briefly, the polygraphic sleep recording included standard electroencephalograph, electro-oculograph and electromyograph of chin muscles. Breathing during sleep was analysed with a Fleisch No. 2 pneumotachograph (Godart, Statham Instruments, Oxnard, CA, USA) attached to a soft Silastic facial mask (No. 3434; Bird Corp, Palm Springs, CA, USA), and by means of either thoracic and abdominal mercury-filled strain gauges or an oesophageal balloon. Transcutaneous oxygen saturation was recorded with a pulse oximeter (Biox III; Ohmeda, Louisville, CO, USA). Central, obstructive and mixed apnoeas were defined according to the usual criteria [2]. Hypopnoeas were defined as a $50 \%$ fall of tidal volume from its value during quiet wakefulness, for at least $10 \mathrm{~s}$.

Systolic and diastolic arterial pressures were measured with a blood pressure cuff during the first visit, with the patient in the supine position for $15 \mathrm{~min}$. Conventional spirometry was performed with a $10 \mathrm{~L}$ closed-circuit spirograph (Repo-test type 602; Meditron, Dargatz, Germany). Static lung volumes were measured by the closed-circuit helium dilution method. Reference values were those of the European Respiratory Society [14].

Right heart catheterization was performed as previously described [15]. Briefly, the haemodynamic measurements were always performed while the patient was awake, in the supine position. For the purpose of this study, small diameter floated catheters, either Grandjean flexopulmocaths (French size No. 4; Plastimed, Saint-Leu-la-Foret, France) or Swan-Ganz catheters (French size No. 5; Edwards Lab Inc, Anasco, Puerto Rico) were used. The catheters were introduced percutaneously into an antecubital or a femoral vein. Cardiac output was calculated according to Fick's equation applied to oxygen during steady-state conditions. Oxygen uptake was measured with a Fleisch closed-circuit spirometer (Metabo, Lausanne, Switzerland) or later during the course of the study with an open circuit-system (Oxycon, Minjhardt, The Netherlands). An 8-min steady-state exercise on a bicycle-ergometer in the supine position was performed when the patient's condition permitted it. The load was 40 W. Mixed venous blood (pulmonary artery) and arterial blood were sampled simultaneously at rest and during the last minute of the exercise in steady-state conditions.
During the second night of the baseline polysomnography, CPAP was given in all patients via a nasal mask with a commercial device. The level of nasal CPAP was gradually increased above the starting level of $2 \mathrm{cmH}_{2} \mathrm{O}$ until apnoeas, hypopnoeas and snoring were abolished. Patients who had persistent nocturnal hypoxaemia in spite of nasal CPAP were treated concomitantly with nocturnal oxygen therapy to achieve an arterial oxygen saturation $\left(S \mathrm{a}_{2} \mathrm{O}_{2}\right)>90 \%$ throughout the night. Home treatment with nasal CPAP was initiated approximately 1 week after the baseline evaluation.

The specific follow-up of the patients included in this study was conducted in two ways. Firstly, control polysomnographies were performed systematically after 1 and 5 yrs of follow-up. The level of CPAP was adjusted during polysomnography if necessary. Secondly, a technician verified the CPAP device at the patient's home and read the time counter. This was carried out every 3 months during the first year of follow-up and every 6 months thereafter. The difference in the time counter readings divided by the duration of treatment was used as an evaluation of the mean daily use of CPAP. In cases of low compliance which could not be resolved at home by a technician, a medical intervention was planned. Long-term drug therapy was prescribed for any associated diseases (i.e. chronic obstructive pulmonary disease (COPD) and systemic arterial hypertension). When the death of a patient was reported, an attempt to establish the primary cause of death was made. All data were captured prospectively in a database. The endpoint of the analysis was August 1, 1995.

\section{Statistics}

SPSS computer software (SPSS Inc. Chicago, IL, USA) was used for all statistical analyses. Values are expressed as the mean \pm SD. Survival rates were calculated according to the Kaplan-Meier method. The assumption of proportional hazards was assessed graphically using the log-minus-log survival plot. Univariate analysis based on the proportional hazards model [16] was used to determine relations between survival rates and covariates. Results are expressed as odds ratio (OR) with the $95 \%$ confidence intervals (CI). Covariates found to be significant $(p<0.05)$ or approaching significance $(\mathrm{p} \leq 0.10)$ according to the univariate analysis were evaluated in a multivariate analysis using a forward stepwise selection [16]. Rejection of the null hypothesis required a p-value of $<0.05$.

\section{Results}

\section{Daytime lung function and pulmonary haemodynamics at baseline}

The population studied consisted of 275 males and 21 females with a mean age of $53 \pm 10$ yrs (range: $30-77$ yrs). Most of the 296 patients were current smokers or exsmokers and obese. The mean values of daytime lung function and pulmonary haemodynamics at baseline are shown on table 1 . The average value of the vital capacity (VC) was normal, whereas average values of forced expiratory volume in one second $(\mathrm{FEV} 1), \mathrm{FEV} 1 / \mathrm{VC}$ ratio and total lung capacity (TLC) were close to the lower limit of the normal range. Fifty-two (18\%) patients had an 
Table 1. - Univariate analysis of survival time related to anthropometric data, lung function, arterial blood gases and pulmonary haemodynamic data collected at baseline

\begin{tabular}{|c|c|c|c|}
\hline Variables & & $\mathrm{OR}^{*}(95 \% \mathrm{CI})$ & p-value ${ }^{+}$ \\
\hline Age yrs & $53 \pm 10$ & $1.07(1.02-1.12)$ & $<0.01$ \\
\hline Smokers $\%$ & 73 & $1.98(0.97-4.08)$ & $=0.063$ \\
\hline Smokers $\geq 30$ pack-yrs $\%$ & 35 & $2.71(1.66-4.43)$ & $<0.001$ \\
\hline $\mathrm{BMI} \mathrm{kg} \cdot \mathrm{m}^{-2}$ & $33 \pm 6$ & $0.99(0.93-1.05)$ & $>0.5$ \\
\hline AI events $\cdot h^{-1}$ & $60 \pm 37$ & $1.00(0.99-1.01)$ & $>0.5$ \\
\hline AHI events $\cdot h^{-1}$ & $78 \pm 33$ & $1.00(0.98-1.01)$ & $>0.5$ \\
\hline $\mathrm{VC} \%$ pred & $94 \pm 17$ & $0.96(0.94-0.98)$ & $<0.001$ \\
\hline FEV $1 \%$ pred & $84 \pm 21$ & $0.96(0.95-0.98)$ & $<0.001$ \\
\hline $\mathrm{FEV} 1 / \mathrm{VC} \%$ & $73 \pm 10$ & $0.93(0.91-0.96)$ & $<0.001$ \\
\hline TLC $\%$ pred & $86 \pm 13$ & $0.96(0.94-0.99)$ & $=0.013$ \\
\hline $\mathrm{Pa}_{\mathrm{a}} \mathrm{O}_{2} \mathrm{mmHg}$ & $73.1 \pm 11.0$ & $0.96(0.93-0.99)$ & $=0.039$ \\
\hline $\mathrm{Pa}_{\mathrm{a}} \mathrm{CO}_{2} \mathrm{mmHg}$ & $39.5 \pm 5.6$ & $1.05(0.99-1.11)$ & $=0.11$ \\
\hline PAP rest $\mathrm{mmHg}$ & $16.0 \pm 5.7$ & $1.08(1.02-1.14)$ & $<0.01$ \\
\hline$P$ pcw rest $\mathrm{mmHg}$ & $6.6 \pm 2.3$ & $1.19(0.95-1.51)$ & $=0.13$ \\
\hline $\mathrm{CO}$ rest $\mathrm{L} \cdot \mathrm{min}^{-\mathrm{P}} \cdot \mathrm{m}^{-2}$ & $2.89 \pm 0.68$ & $1.37(0.71-2.63)$ & $=0.35$ \\
\hline PVR rest $\mathrm{mmHg} \cdot \mathrm{L}^{-1} \cdot \mathrm{min}^{-1}$ & $1.55 \pm 0.84$ & $1.49(0.96-2.31)$ & $=0.072$ \\
\hline PAP exercise $\mathrm{mmHg}$ & $30.6 \pm 10.7$ & $1.08(1.04-1.12)$ & $<0.001$ \\
\hline SAP $\mathrm{mmHg}$ & $148 \pm 13$ & $0.99(0.97-1.02)$ & $>0.5$ \\
\hline DAP $\mathrm{mmHg}$ & $92 \pm 10$ & $0.98(0.93-1.31)$ & $=0.42$ \\
\hline
\end{tabular}

Data are presented as mean \pm SD or percentages. OR: odds ratio; CI: confidence interval; BMI: body mass index; AI: apnoea index; AHI: apnoea/hypopnoea index; VC: vital capacity; $\mathrm{FEV}$ : forced expiratory volume in one second; TLC: total lung capacity; $P \mathrm{a}, \mathrm{O}_{2}$ : arterial oxygen tension; $P \mathrm{a}, \mathrm{CO}_{2}$ : arterial carbon dioxide tension; PAP: mean pulmonary artery pressure; $P$ pcw: pulmonary capillary wedge pressure; CO: cardiac output; PVR: pulmonary vascular resistance; SAP: systolic arterial blood pressure; DAP: diastolic arterial blood pressure. *: exponential $(\beta){ }^{+}$: significant level of the likelihood-ratio test; ${ }^{\dagger}$ : categorical covariate. $(1 \mathrm{mmHg}=0.133 \mathrm{kPa}$. $)$

obstructive spirographic pattern, defined by an FEV1/VC ratio $\leq 65 \%$. Eighty $(27 \%)$ patients, all of them being markedly obese, had a restrictive ventilatory defect, defined as a TLC $<80 \%$ of the predicted value. When considering a low FEV1, it must be mentioned that it was mainly owing to an associated COPD, since among the 69 patients with an FEV $1<70 \%$ of the predicted value only five had a pure restrictive pattern

\section{Baseline sleep parameters and CPAP compliance}

By definition, the 296 patients included had a polysomnographic confirmation of the clinically suspected diagnosis of OSA (table 1). The rate of disordered breathing events was high, mean 78 apnoeas/hypopnoeas $\cdot \mathrm{h}^{-1}$ but there was a large deviation of individual results $(\mathrm{SD}=33)$. The average effective CPAP for the group as a whole was 9.6 $\pm 3.0 \mathrm{cmH}_{2} \mathrm{O}$ (range: $4-18 \mathrm{cmH}_{2} \mathrm{O}$ ) which was the mean pressure used in the first year of treatment. The level of CPAP was decreased to $8.9 \pm 2.6 \mathrm{cmH}_{2} \mathrm{O}$ in the 281 patients who underwent a second polysomnography after $1 \mathrm{yr}$ of follow-up and to $8.6 \pm 2.8 \mathrm{cmH}_{2} \mathrm{O}$ after $5 \mathrm{yrs}$ of follow-up in 109 patients. The mean duration of the follow-up of the 296 patients which corresponds to the mean duration of CPAP treatment was $4.9 \pm 2.1$ yrs (range: 0.6-11.5 yrs). During follow-up, most patients reported good adaptation to the CPAP. The distribution of the mean daily use of CPAP by brackets of one year is shown in figure 1 . The mean was always $>5 \mathrm{~h} \cdot$ night $^{-1}$ and none of the 296 patients had a mean daily use of CPAP of $\leq 2$ $\mathrm{h} \cdot$ night $^{-1}$ during two consecutive 6 -month periods. Eleven patients were treated with nocturnal oxygen therapy (6-8 $\mathrm{h} \cdot$ night $^{-1}$ ) in conjunction with nasal CPAP.

From the 296 patients, 41 were no longer followed up as part of the present study at the endpoint (August 1, 1995). Four patients had an apnoea/hypopnoea index $<20$ at a polysomnography re-evaluation and an improvement of clinical symptoms of OSA. Accordingly, home nasal CPAP in these four patients was stopped. Thirteen patients moved to another part of the country. The remaining 24 patients decided to stop nasal CPAP, they either declared themselves cured or not sufficiently ill to continue home nasal CPAP. The survival time of these 41 patients who were not followed up until the endpoint was censored at the date of the last visit and included in the statistical analysis.

\section{Survival rates of the patients and causes of death}

At the end of the study 26 of the 296 (9\%) patients had died, who were all males. The cumulative survival function

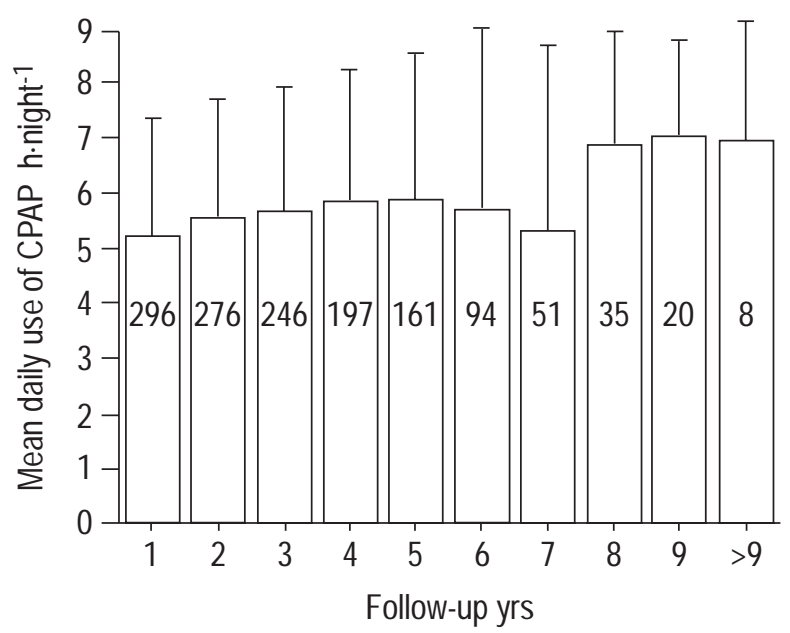

Fig. 1. - Distribution of the mean \pm SD daily use of continuous positive airway pressure (CPAP) by brackets of one year of follow-up. The figures inside each column correspond to the number of patients. 
for the group as a whole is shown in figure 2. The cumulative survival rates were 0.96 (95\% CI: $0.94-0.99)$ at 3 yrs and 0.93 (95\% CI: $0.91-0.97)$ at 5 yrs. A death certificate was obtained after 22 deaths. The most prevalent cause of death was myocardial infarction or sudden death following chest pain which occurred in 10 patients (never during the use of nasal CPAP). The second most prevalent cause of death was neoplastic disease; five patients died from cancer, three of them had lung carcinoma. Four patients died in an intensive care unit following an acute respiratory failure. These four patients had an associated COPD. Two patients committed suicide and one patient died from a stroke.

\section{Univariate analysis}

Results of the univariate analysis which determines the relation between survival and covariates measured at the entry into the study are shown in table 1 . All covariates except "smokers" and "smokers $>30$ pack-yrs" are continuous variables. Interestingly, obesity did not contribute to increased mortality. It was observed that the most statistically significant predictors of death were heavy smoking habit, VC (\% pred), FEV1 (\% pred), FEV1/VC ratio and exercising mean pulmonary artery pressure (PAP). Indeed, the risk of death among patients who had smoked $>30$ pack-yrs was significantly higher compared to the remainder (OR: 2.71; 95\% CI: 1.66-4.43). In order to illustrate the quite different life expectancy in patients who had an associated COPD compared to the remainder, the $\mathrm{FEV} 1 / \mathrm{VC}$ ratio was transformed as a categorical covariate with a cut-off value of $65 \%$ (fig. 2 ). The cumulative survival rate at $5 \mathrm{yrs}$ of the 52 patients with an $\mathrm{FEV} 1 / \mathrm{VC}$ ratio $<65 \%$ was 0.79 (95\% CI: $0.67-0.90)$ versus 0.97 (95\% CI: 0.95-0.99) in the remainder ( $\mathrm{p}<$ $0.001)$, the OR being 2.25 (95\% CI: 1.53-3.31). Survival was also associated with age, TLC ( $\%$ pred), arterial oxygen tension $\left(\mathrm{Pa}, \mathrm{O}_{2}\right)$ and PAP at rest, but to a lesser degree. Given that age could be a confounding factor, the univariate analysis was stratified by age with a median

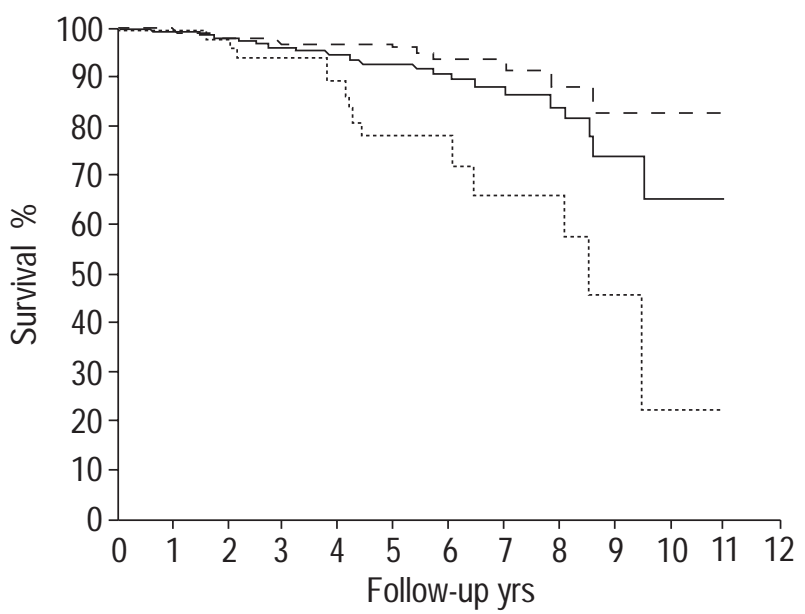

Fig. 2. - Kaplan-Meier survival curve of the group as a whole ( - ) and for patients divided according to forced expiratory volume in one second (FEV1) vital capacity (VC) ratio with a cut-off value of $65 \%$ $(>65 \%$ : $--;<65 \%$ : - - - - ). There was a significant difference $(\mathrm{p}<0.001)$ between the $\mathrm{FEV} 1 / \mathrm{VC}>65 \%$ and $\mathrm{FEV} 1 / \mathrm{VC}<65 \%$ groups. cut-off value of 53.4 yrs. The differences of survival rates according to all these predictors of death remained statistically significant except for $\mathrm{Pa}_{\mathrm{a}} \mathrm{O}_{2}$.

\section{Multivariate analysis}

The multiple proportional hazards analysis examined the independent effect on mortality of age, smoking habit, VC ( $\%$ pred), FEV1 ( $\%$ pred), TLC ( $\%$ pred), $\mathrm{Pa}_{\mathrm{a}} \mathrm{O}_{2}, \mathrm{PAP}$ and pulmonary vascular resistance (PVR). Three covariates, smoking habit ( $>30$ pack-yrs as a categorical variable), age and FEV1 were included by forward stepwise selection in the equation (table 2). Thus, with the exception of age, the independent contributing factors of death in this group of patients were firstly a smoking history of $>30$ pack-yrs and secondly the presence of a decreased FEV1 mainly owing to an associated obstructive airway disease.

\section{Discussion}

The present study shows that in this large series of 296 unselected OSA patients treated with home nasal CPAP, the cumulative survival rates were 0.96 (95\% CI: 0.94 0.99 ) and 0.93 (95\% CI: $0.91-0.97)$ at 3 and 5 yrs of follow-up, respectively. The most prevalent cause of death was cardiovascular disease, followed by neoplastic disease and acute respiratory failure. It was observed that the most significant and independent predictors of death were a smoking history $>30$ pack-yrs and the presence of an associated obstructive lung disease.

This series of 296 patients is composed of all patients seen at a sleep laboratory for OSA during a well-defined period of time and accepting home nasal CPAP as therapy. The criteria for prescribing home CPAP used in this study were those commonly accepted [17] and were unchanged throughout the study. It must be emphasized that firstly, all patients were recruited from a sleep laboratory which is part of a department of neurology, and secondly, the reasons which led to the referral of the patients to the sleep laboratory were mainly snoring and excessive daytime somnolence. From this, it is assumed that this series of 296 patients is representative of OSA patients seen at a sleep laboratory and treated with home nasal CPAP. It could be argued that $73 \%$ is a too high prevalence of smokers or exsmokers in a population of OSA patients. However, a national survey [18] has shown that the percentage of smokers or exsmokers in adult French males was $71 \%$ in 1987 . Therefore, since cigarette smoking is a strong independent risk factor for sleep disordered breathing [19] it is not surprising to find such a

Table 2. - Results of the multivariate analysis

\begin{tabular}{lcc}
\hline Variables & OR* $^{*}(95 \%$ CI $)$ & p-value $^{\dagger}$ \\
\hline Smokers $>30$ pack-yrs* & $2.71(1.66-4.43)$ & $<0.001$ \\
Age yrs & $1.05(1.01-1.10)$ & $=0.01$ \\
FEV1 \% pred & $0.98(0.96-0.99)$ & $=0.02$ \\
\hline
\end{tabular}

OR: odds ratio; CI: confidence interval; FEV1: forced expiratory volume in one second. *: exponential $(\beta) ;{ }^{\dagger}$ : significance level of the likelihood-ratio test from the previous step; ${ }^{\star}$ : categorical covariate. 
prevalence of smokers or exsmokers in the present population.

There could be another bias, if the 41 patients no longer treated with nasal CPAP at the endpoint were included in the survival analysis, but had stopped nasal CPAP because of worsening of the disease or death. This point was carefully checked at the time of stopping CPAP and it was confirmed that of these 41 patients, four were cured and 14 were still alive at the endpoint. Moreover, no statistical difference was observed for all variables collected at baseline between these 41 patients and the 229 survivors who were treated with nasal CPAP until the endpoint.

To answer the most important question "Is home nasal CPAP protective against the increased mortality which has been advocated in OSA?", the mortality rates of the present study were compared with those provided by the French National Institute of Statistics (INSEE) for males for the years 1988-1990 [20]. The expected number of deaths were calculated for males of the general population during a similar follow-up and compared using Fischer's exact test [21] stratified by the 4th, 5th, 6th, 7th and 8th decades. As mentioned above, the prevalence of smokers or exsmokers among adult French males in the late 1980 s was $\sim 70 \%$ [18]. Therefore, the population constructed was matched in terms of age (at the last visit or death), sex and smoking habit. The difference was statistically significant for the 6th decade, but not for the other age groups. Indeed, the observed death rate was eight in 101 patients of the present study between 50-60 yrs of age, compared to one estimated death rate in the general population $(\mathrm{p}=0.038)$. However, when the 52 patients with an associated COPD ( $\mathrm{FEV} 1 / \mathrm{VC} \leq 65 \%)$ were excluded from this comparison the difference noticed in the 6th decade was no longer significant. This comparison suggests that the mortality rate in the treated patients is similar to that of the general population, with the exception of the patients between 50 and $60 \mathrm{yrs}$ of age when a COPD is associated to OSA.

PARTINEN et al. [4] observed 14 deaths in 127 OSA patients conservatively managed (weight loss) in contrast to no observed death in a "tracheostomy" group of 71 patients. These authors [4] were the first to provide information on the comorbidity and causes of death of OSA patients. The commonest cause of death was cardiovascular disease. Similarly, in the present study, most of the deaths had a cardiovascular basis. In the 22 welldocumented deaths of the present study, 11 were of cardiovascular origin (10 myocardial infarctions and one stroke). These 11 patients were, on the whole, compliant to home nasal CPAP, since the mean daily use of CPAP for the entire period of follow-up was 5.2 $\pm 2.1 \mathrm{~h} \cdot$ night $^{-1}$ (range: $2.3-7.9 \mathrm{~h} \cdot$ night $^{-1}$ ), and only two patients had a mean daily use of CPAP $<4 \mathrm{~h}$. It was not possible to provide data on daily use of CPAP during the month preceding death in these patients. The fact that OSA patients died mainly from myocardial infarction has also been observed in two other studies $[22,23]$ in which the majority of the patients did not receive CPAP therapy. Consequently, most of the deaths in OSA patients whether or not treated with nasal CPAP are due to cardiovascular disease.

One important finding of the present study relates to the smoking history of the 296 patients. It has been shown that smoking is a risk factor for sleep disordered breathing [19] and contributes to the decline of the FEV1 in OSA patients receiving CPAP [11]. Moreover, the present study shows that OSA patients receiving CPAP who were current or exsmokers had an increased risk of death (table 1), probably owing to increased comorbidity (cardiovascular disease, cancer and COPD). Although it is now clear that cigarette smoking is predictive of a poor life expectancy, this result further emphasizes the harmful effect of tobacco in terms of both morbidity and mortality.

In the present study, it was observed that the risk of death is higher in OSA patients with COPD who receive CPAP compared to similarly treated patients without evidence of COPD (table 1 and fig. 2). The association of the two diseases, the so-called "overlap syndrome" [24], makes a major contribution in the progression towards chronic respiratory failure and pulmonary hypertension when OSA is untreated [25]. Furthermore, LAVIE et al. [23] have observed that the presence of coexistent lung disease is a significant predictor of death in untreated or conservatively treated OSA patients. All patients from the present study were treated with nasal CPAP and "overlap" patients were as compliant to home nasal CPAP as the remainder (the mean daily use of CPAP was $6.6 \pm 1.6$ $\mathrm{h} \cdot$ night $^{-1}$ in the "overlap" patients versus $5.8 \pm 1.7 \mathrm{~h} \cdot$ night $^{-1}$ in the remainder). The fact that a decreased FEV1 was, independent of smoking habits, a factor related to reduced survival, reflects that FEV1 is the best predictor of mortality in COPD [26]. Furthermore, in a recent study PeKer et al. [27] have observed that nasal CPAP reduced hospitalization in OSA patients with cardiovascular and pulmonary diseases. Therefore, although nasal CPAP is an important part of the therapy, "overlap" patients remain at risk of fatal myocardial infarction due to confounding risk factors for OSA, COPD and cardiovascular diseases.

It was also observed that increased PAP at the time of entry into the study was a predictor of death in OSA patients receiving nasal CPAP. However, this factor of reduced survival disappeared in favour of FEV1 in the multivariate analysis. Subsequently, the present results confirm that pulmonary hypertension is most often due to an associated COPD [13].

Finally, blood pressure, baseline severity of OSA and overall compliance with nasal CPAP (data not shown) were not related to survival rate in the present study. As regards to the severity of OSA quantified by the apnoea index and AHI, since all patients were treated and had an overall good compliance a negative result was expected. On the other hand with regard to blood pressure and compliance with CPAP, considering that a type II error (probability of accepting a false null hypothesis) was not assessed it cannot be excluded that a higher number of patients would allow a positive result to be obtained. Therefore, no conclusion can be drawn from these latter negative results.

In conclusion, survival rates of obstructive sleep apnoea patients treated with nasal continuous positive airway pressure are near to those of the general population. Most of the patients die from cardiovascular disease. The prognosis is worse in subgroups of patients with a history of heavy smoking and with associated obstructive airway disease.

Acknowledgements. The authors thank E. Chailleux and R. Marcus for their assistance. 


\section{References}

1. Young T, Palta M, Dempsey J, Skatrud J, Weber S, Badr $\mathrm{S}$. The occurrence of sleep-disordered breathing among middle-aged adults. $N$ Engl J Med 1993; 328: 12301235 .

2. Guilleminault C, Tilkian A, Dement WC. The sleep apnoea syndromes. Annu Rev Med 1976; 27: 465-484.

3. Bradley TD, Rutherford A, Grossmann RF, et al. Role of daytime hypoxemia in the pathogenesis of right heart failure in the obstructive sleep apnea syndrome. Am Rev Respir Dis 1985; 131: 835-839.

4. Partinen M, Jamieson A, Guilleminault C. Long-term outcome for obstructive sleep apnea syndrome patients: mortality. Chest 1988; 94: 1200-1204.

5. He J, Kryger MH, Zorick FJ, Conway W, Roth T. Mortality and apnea index in obstructive sleep apnea. Experience in 385 male patients. Chest 1988; 94: 9-14.

6. Sullivan CE, Issa FG, Berthon-Jones M, Eves L. Reversal of obstructive sleep apnoea by continuous positive airway pressure applied through the nares. Lancet 1981; 1: 862865.

7. Collard Ph, Pieters Th, Aubert G, Delguste P, Rodenstein DO. Compliance with nasal CPAP in obstructive sleep apnea patients. Sleep Med Rev 1997; 1: 33-44.

8. Leech JA, Önal E, Lopata M. Nasal CPAP continues to improve sleep-disordered breathing and daytime oxygenation over long-term follow-up of occlusive sleep apnea syndrome. Chest 1992; 102: 1651-1655.

9. Young IH, Mihalyka M, Costas L, Sullivan CE. Long term lung function changes in patients with obstructive sleep apnea during treatment with nasal continuous positive airway pressure. Thorax 1987; 42: 722.

10. Sforza E, Krieger J, Weitzenblum E, Apprill M, Lampert E, Ratamaharo E. Long-term effects of treatment with nasal continuous positive airway pressure on daytime lung function and pulmonary hemodynamics in patients with obstructive sleep apnea. Am Rev Respir Dis 1990; 141: 866-870.

11. Chaouat A, Weitzenblum E, Kessler R, et al. Five-year effects of nasal continuous positive airway pressure in obstructive sleep apnoea syndrome. Eur Respir J 1997; 10: 2578-2582.

12. Crowe-McCann C, Nino-Murcia G, Guilleminault C. Nasal CPAP. The Stanford experience. In: Guilleminault C, Partinen M, eds. Obstructive Sleep Apnea Syndrome. New York, Raven Press, 1990; pp. 119-127.
13. Chaouat A, Weitzenblum E, Krieger J, Oswald M, Kessler R. Pulmonary hemodynamics in the obstructive sleep apnea syndrome: results in 220 consecutive patients. Chest 1996; 109: 380-386.

14. Quanjer PH, Tammeling GJ, Cotes JE, Pedersen OF, Peslin R, Yernault JC. Lung volumes and forced ventilatory flows. Eur Respir J 1993; 6: Suppl. 16, 15-40.

15. Weitzenblum E, Loiseau A, Hirth C, Mirhom R, Rasaholinjanahary J. Course of pulmonary hemodynamics in patients with chronic obstructive pulmonary disease. Chest 1979; 75: 656-662.

16. Collett D. Modeling Survival Data in Medical Research, 1st Edn. London, Chapman \& Hall, 1994; pp. 53-106.

17. Berry RB, Block AJ. Positive nasal airway pressure eliminates snoring as well as obstructive sleep apnea. Chest 1984; 85: 15-20.

18. Hirsch A, Hill C, Frossard M, Tassin JP, Pechabrier M. Lutte contre le tabagisme. La Documentation Française. Paris, Masson, 1988.

19. Wetter DW, Young TB, Bidwell TR, Badr MS, Palta M. Smoking as a risk factor for sleep disordered breathing. Arch Intem Med 1994; 154: 2219-2224.

20. République Française. Ministère de l'économie et des finances. Institut national de la statistique et des études économiques. La situation démographique en France en 1990. Demographie - Sociéte 1992; 149; 16-17.

21. Kirkwood BR. Essentials of Medical Statistics. 1st Edn. Oxford, Blackwell Science, 1988; pp. 94-105.

22. Gonzalez-Rothi RJ, Foresman GE, Block AJ. Do patients with sleep apnea die in their sleep? Chest 1988; 94 : 531-538.

23. Lavie P, Herer P, Peled R, et al. Mortality in sleep apnea patients: a multivariate analysis of risk factors. Sleep 1995; 18: 149-157.

24. Flenley DC. Sleep in chronic obstructive lung disease. Clin Chest Med 1985; 6: 51-61.

25. Chaouat A, Weitzenblum E, Krieger J, Ifoundza T, Oswald M, Kessler R. Association of chronic obstructive pulmonary disease and sleep apnoea syndrome. Am J Respir Crit Care Med 1995; 151: 82-86.

26. Anthonisen NR, Wright EC, Hodgkin JE, and the IPPB Trial Group. Prognosis in chronic obstructive pulmonary disease. Am Rev Respir Dis 1986; 133: 14-20.

27. Peker Y, Hedner J, Johansson A, Bende M. Reduced hospitalization with cardiovascular and pulmonary disease in obstructive sleep apnoea patients on nasal CPAP treatment. Sleep 1997; 20: 645-653. 